\title{
Glucose abnormalities in Asian patients with chronic hepatitis $C$
}

This article was published in the following Dove Press journal:

Drug Design, Development and Therapy

9 November 2015

Number of times this article has been viewed

\author{
Qingyan Bo' \\ Roberto Orsenigo 2 \\ Junyi Wang' \\ Louis Griffel ${ }^{3}$ \\ Clifford Brass ${ }^{3}$
}

'Beijing Novartis Pharma Co. Ltd., Shanghai, People's Republic of China; ${ }^{2}$ Novartis Pharma AG, Basel, Switzerland; ${ }^{3}$ Novartis Pharmaceuticals Corporation, East Hanover, NJ, USA
Correspondence: Qingyan Bo Beijing Novartis Pharma Co. Ltd., 3।

Yong'an Rd, Changping, Shanghai 20I203,

People's Republic of China

Tel +862 2I 22238665

Fax +862123218100

Email bqy2015@126.com
Abstract: Many studies have demonstrated a potential association between type 2 diabetes (T2D) and hepatitis C virus infection in Western countries, while similar evidence is limited in Asia. We compared the prevalence of glucose abnormalities (impaired fasting glucose [IFG] and T2D) and their risk factors between Asian and non-Asian chronic hepatitis $\mathrm{C}$ (CHC) patients, and evaluated whether glucose abnormalities impacted the viral responses to peginterferon plus ribavirin treatment (current standard of care in most Asian countries). This study retrospectively analyzed data of 1,887 CHC patients from three Phase II/III studies with alisporivir (DEB025) as treatment for $\mathrm{CHC}$. The chi-square test was used to compare the prevalence of IFG/T2D between Asian and non-Asian CHC patients, and logistic regression was used to adjust for sex, age, and cirrhosis status. Risk factors for IFG/T2D were evaluated using univariate and multivariate analysis. Our results indicated that the prevalence of IFG/T2D was high in both Asian and non-Asian CHC patients (23.0\% vs 20.9\%), and no significant difference was found between these two populations (adjusted odds ratio: 1.3, 95\% confidence interval: $0.97,1.7$; $P=0.08$ ). Age, sex, and cirrhosis status were risk factors for IFG/T2D in both populations, while body mass index was positively associated with IFG/T2D in non-Asian but not in Asian participants. No significant differences in sustained virological response rates were seen between patients with normal fasting glucose and patients with IFG/T2D for both populations. These results demonstrate that the prevalence of glucose abnormalities in Asian CHC patients was similar to that in non-Asians, and glucose abnormalities had no impact on viral response to peginterferon plus ribavirin.

Keywords: $\mathrm{CHC}$, type 2 diabetes, risk factor, alisporivir

\section{Introduction}

Hepatitis $\mathrm{C}$ virus (HCV) is a blood-borne virus of the Flaviviridae family and one of the leading causes of chronic liver disease. Approximately $2.35 \%$ of the world's population or 185 million people are infected with $\mathrm{HCV} .{ }^{1}$ Many HCV-infected subjects may develop cirrhosis and/or hepatocellular carcinoma, which result in increased mortality. ${ }^{2}$ It is well recognized that liver damage is the main cause of increased morbidity and mortality among HCV patients. However, other syndromes associated with HCV infection, such as glucose metabolic abnormalities, are also shown to play a role in increased morbidity and mortality. ${ }^{2}$ Impaired fasting glucose (IFG) and type 2 diabetes (T2D) are two common categories of abnormal glucose metabolism. Several clinical or epidemiological studies have demonstrated a potential association between T2D and chronic HCV infection, suggesting that chronic HCV infection significantly increased the risk of developing glucose metabolism alterations, insulin resistance, and, consequently, overt T2D. ${ }^{3-10}$ In a prospective case-cohort study including 1,084 adults, HCV-positive patients who also carried a high risk of 
developing diabetes (based on body mass index [BMI] and age) were eleven times more likely to actually develop diabetes than HCV-negative individuals who carried the same risk factors. However, this effect was not found in patients at low risk of developing diabetes. ${ }^{11}$ Notably, most of the relevant data were generated in Western countries, with a higher prevalence of obesity than their Eastern counterparts, and where T2D patients were older than those in Asian countries. Sporadic publications in the People's Republic of China have suggested a higher incidence of T2D in chronic hepatitis $\mathrm{C}(\mathrm{CHC})$ populations, but sample sizes were very small. ${ }^{12,13}$ Therefore, it is still unclear whether chronic HCV infection exerts a similar diabetogenic effect in the Asian population as it does in Western population. A peginterferon plus ribavirin (pegIFN/RBV) regimen had been the standard of care worldwide for many years for treatment of $\mathrm{CHC}$ before the launch of the first direct antiviral agent in 2011, but the regimen is still standard of care in most Asian countries. ${ }^{14,15}$ One study in Spain with 1,059 CHC patients reported that the sustained virological response (SVR) rate to pegIFN was $15 \%$ lower in patients with IFG/T2D than in those with normal glucose concentrations. ${ }^{16}$ Similar data are deficient in Asia.

This study used the database from the alisporivir (ALV) development program to compare the prevalence of glucose abnormalities (IFG/T2D) between Asian and non-Asian CHC patients and to evaluate risk factors of IFG/T2D in these two populations. In addition, we also evaluated the distribution pattern of viral responses to pegIFN/RBV treatment by glucose abnormalities in Asian CHC patients.

\section{Methods}

\section{Study design and population}

Three large, international, prospective, randomized, Phase II/III clinical trials A2210 (NCT01183169), A2301 (NCT01318694), and A2211 (NCT01215643), sponsored by Novartis Pharma AG, have investigated the use of different doses of ALV with pegIFN/RBV in genotype $1 \mathrm{CHC}$ and with/without pegIFN/RBV in genotype 2/genotype $3 \mathrm{CHC}$. From 2009 to 2013, 1,887 CHC patients from around the world were enrolled. The patient population and participating countries are listed in Table 1. These studies combined South Asians (mainly Indians) with East Asians. Despite substantial cultural and linguistic diversity among Asians, the HUGO Pan-Asian SNP Consortium human genetic diversity study showed that genetic ancestry was strongly correlated and genetically similar among these groups; ${ }^{17}$ this supported the pooling of all Asians together in this analysis.

The common diagnosis and main criteria for inclusion or exclusion for the three studies included: 1) male or female CHC patients aged between 18 and 70 years old; 2) BMI between 18 and $36 \mathrm{~kg} / \mathrm{m}^{2}$; 3) exclusion of subjects coinfected with hepatitis B virus or HIV, with other causes of liver disease, or with clinical evidence of decompensated liver disease; and 4) exclusion of patients with history of pancreatitis or uncontrolled diabetes mellitus (defined by fasting glucose $>7.77 \mathrm{mmol} / \mathrm{L}[140 \mathrm{mg} / \mathrm{dL}]$ and $\mathrm{HbA}_{1 \mathrm{c}}>7.5 \%$ ).

Cirrhosis status was defined in this study as cirrhosis/ bridging fibrosis: by an elasticity score $\geq 10.8 \mathrm{kPa}$ on FibroScan ${ }^{\circledR 18}$ or Metavir score 3/4/Ishak score 5-6 on liver biopsy. Patients with compensated cirrhosis were allowed in studies A2210 and A2301, while patients with cirrhosis were excluded in study A2211. In study A2211, cirrhosis was defined either by fibrosis measurement (such as FibroScan, liver biopsy, etc) or only by clinical manifestation. Hence, many patients in study A2211 did not have quantitative data on fibrosis evaluation, which led to many missing data for the variable cirrhosis or bridging fibrosis.

\section{Ethical considerations}

All three studies were reviewed and approved by the appropriate institutional ethics committees and health authorities. All patients provided written informed consent.

Table I Patient data from three Phase II/III clinical trials

\begin{tabular}{|c|c|c|c|c|c|}
\hline \multirow{2}{*}{$\begin{array}{l}\text { Study numberl } \\
\text { Phase }\end{array}$} & \multicolumn{3}{|c|}{ Patient population (FAS) } & \multicolumn{2}{|c|}{ Participating countries/regions } \\
\hline & Genotype & Treatment & $\mathbf{N}$ & Asian & Non-Asian \\
\hline $\begin{array}{l}\text { A230I/Phase III } \\
\text { NCT0II83I69 }\end{array}$ & I & Naïve & $\mathrm{I}, 085$ & $\begin{array}{l}\text { Hong Kong, South } \\
\text { Korea, Taiwan, } \\
\text { Thailand, Vietnam }\end{array}$ & $\begin{array}{l}\text { Belgium, France, Germany, Hungary, Italy, Poland, } \\
\text { Romania, Spain, United Kingdom, Argentina, } \\
\text { Australia, Canada, Mexico, Russia, USA }\end{array}$ \\
\hline $\begin{array}{l}\text { A2210/Phase II } \\
\text { NCT0I318694 }\end{array}$ & I & Experienced & 461 & Taiwan, Turkey & $\begin{array}{l}\text { Australia, Belgium, France, Germany, Hungary, Italy, } \\
\text { Poland, Romania, Spain, United Kingdom, USA }\end{array}$ \\
\hline $\begin{array}{l}\text { A22II/Phase II } \\
\text { NCT0I2I5643 }\end{array}$ & 2 or 3 & Naïve & 341 & $\begin{array}{l}\text { India, South Korea, } \\
\text { Taiwan, Thailand }\end{array}$ & $\begin{array}{l}\text { Belgium, France, Germany, Italy, Poland, United } \\
\text { Kingdom. Non-EU: Australia, Canada, USA }\end{array}$ \\
\hline
\end{tabular}

Abbreviation: FAS, full analysis set. 


\section{Data collection}

The blood samples collected in all three studies were analyzed by central laboratories. Blood was drawn at every visit after at least 4 hours of fasting. Fasting glucose was measured at both screening and baseline visit, while $\mathrm{HbA}_{1 \mathrm{c}}$ was measured only at screening.

\section{Glucose abnormalities data}

Glucose abnormalities data (IFG/T2D) were collected and evaluated by using medical history, prior concomitant medications, and laboratory data collected in ALV studies. IFG and T2D were identified by using the following methods and criteria:

1. Medical history and prior concomitant medications were searched using narrow search preferred terms in the Standardised MedDRA Query (SMQ) "Hyperglycaemia/ new onset diabetes mellitus" (MedDRA version 16.1), while excluding obvious non-T2D terms, such as type 1 diabetes mellitus, type 3 diabetes mellitus, neonatal diabetes mellitus, latent autoimmune diabetes in adults, pancreatogenous diabetes, etc. All the program-selected terms were manually checked and confirmed by qualified medical doctors.

2. If medical history and prior concomitant medications did not confirm IFG or T2D, we used the following criteria based on available lab data prior to the start of study treatment (screening or baseline measurement): the American Diabetes Association (ADA) diagnostic criteria issued in $2010^{19}$ and World Health Organization (WHO) definition issued in 2006. ${ }^{20}$ The diagnosis criteria were: 1) fasting glucose $<6.1 \mathrm{mmol} / \mathrm{L}(<110 \mathrm{mg}$ ) $\mathrm{dL}$ ) and $\mathrm{HbA}_{1 \mathrm{c}}<6.0 \%$ : normal; 2) fasting glucose $\geq 6.1$ and $<7.0 \mathrm{mmol} / \mathrm{L}$ ( $\geq 110$ and $<126 \mathrm{mg} / \mathrm{dL}$ ) and $\mathrm{HbA}_{1 \mathrm{c}} \geq 6.0 \%$ and $\leq 6.4 \%$ : impaired fasting glycemia; and 3) fasting glucose $\geq 7.0 \mathrm{mmol} / \mathrm{L}(\geq 126 \mathrm{mg} / \mathrm{dL})$ and $\mathrm{HbA}_{1 \mathrm{c}} \geq 6.5 \%$ : diabetes mellitus.

The prevalence of T2D and IFG/T2D in Asia and Western countries was also estimated from International Diabetes Federation (IDF) 2013, ${ }^{21}$ to be compared with the prevalence of T2D and IFG/T2D in Asian and non-Asian CHC patients.

\section{Other potential risk factors}

Other potential risk factors for IFG and T2D, such as sex, BMI, age, smoking, alcohol consumption, and fibrosis status, were collected before study treatment at screening or baseline visits. Although waist-to-hip ratio was reported to be a stronger predictor of diabetes than BMI in Asians, ${ }^{22}$ our study only collected BMI. BMI was calculated by dividing the weight (in $\mathrm{kg}$ ) of the patient by the square of their height $\left(\right.$ in $^{2}{ }^{2}$ ). Alcohol intake was defined as none (nondrinker) or yes (greater than or equal to one drink/day or $14 \mathrm{~g}$ of alcohol). However, alcohol consumption $>20 \mathrm{~g} /$ day for females and $>30 \mathrm{~g} /$ day for males was an exclusion criterion for all three studies.

For virology assessments, HCV genotyping was performed with the VERSANT ${ }^{\circledR} \mathrm{HCV}$ Genotype 2.0 assay (LiPA). SVR data from all CHC patients who were randomized in the control arm and received pegIFN/RBV were evaluated to see if glucose abnormalities had an impact on viral response. The rs12979860 (C>T) genotype in the IL28B locus was assessed in serum samples by using Custom TaqMan SNP Genotyping Assays at the screening visit in studies A2210 and A2301 for HCV genotype 1 patients only.

\section{Statistical analysis}

Demographic information and baseline disease characteristics of the participants were recorded as mean \pm standard deviation for continuous variables and number (percentage) for categorical variables. Comparisons between Asian and non-Asian CHC patients in demographic and baseline variables were conducted using a Student's $t$-test for continuous variables and chi-square tests for categorical variables. Subclassification analysis was done for different glucose statuses (normal glucose, IFG/T2D). Univariate logistic regression was done to test the potential risk factors of the glucose abnormality of the participants. A multivariate logistic regression model was then adopted to find the predictive factors among those significant in the previous univariate analyses. Chi-square tests were carried out to evaluate the relationships among different races and their blood glucose levels. Logistic regression was then carried out to adjust for the risk factors of the glucose abnormality in both Asian and non-Asian $\mathrm{CHC}$ patients. All of the above hypothesis tests were two-sided, and a $P$-value of 0.05 or less was considered to indicate statistical significance.

\section{Results}

\section{Demographic and other baseline characteristics}

Of the $1,887 \mathrm{CHC}$ patients enrolled in this study, $30.2 \%$ were Asian, while the other $69.8 \%$ were non-Asian (Table 2). The number of patients above 45 years old was greater in Asians than in non-Asians. There were no significant differences between Asians and non-Asians in the number of male patients. More patients were obese among non-Asians than Asians. For Asian patients, 74.2\% had IL28B CC, 25.8\% had CT/TT; for non-Asian patients, $24.0 \%$ had IL28B CC, $75.5 \%$ had CT/TT. 
Table 2 Demographic and other baseline characteristics

\begin{tabular}{|c|c|c|c|}
\hline Demographic variables & $\begin{array}{l}\text { Non-Asian } \\
(\mathrm{N}=|, 3| 7)\end{array}$ & $\begin{array}{l}\text { Asian } \\
(\mathrm{N}=570)\end{array}$ & $P$-value ${ }^{a}$ \\
\hline Age (years) & $46.6 \pm 11.4$ & $45.5 \pm 11.8$ & ND \\
\hline Age category (years)** & & & $<0.01$ \\
\hline$<45$ & $480(36.5)$ & $269(47.3)$ & \\
\hline$\geq 45$ & $837(63.6)$ & $300(52.7)$ & \\
\hline Sex & & & 0.07 \\
\hline Male & $760(57.5)$ & $354(62.1)$ & \\
\hline Female & $557(42.3)$ & $216(37.9)$ & \\
\hline BMI $\left(\mathrm{kg} / \mathrm{m}^{2}\right)$ & $26.4 \pm 4.2$ & $24.4 \pm 3.8$ & ND \\
\hline BMI category $\left(\mathrm{kg} / \mathrm{m}^{2}\right)^{* *}$ & & & $<0.01$ \\
\hline$\geq 30$ & $253(19.3)$ & $31(5.4)$ & \\
\hline$\geq 25$ and $<30$ & $527(40.2)$ & $192(33.7)$ & \\
\hline$<25$ & $532(40.6)$ & $347(60.9)$ & \\
\hline Cirrhosis or bridging fibrosis & & & 0.06 \\
\hline Yes & $252(2 \mathrm{I} .2)$ & $81(17.1)$ & \\
\hline No & $937(78.8)$ & $393(82.9)$ & \\
\hline Smoking** & & & $<0.01$ \\
\hline Yes & $573(43.7)$ & $|8|(3 \mid .8)$ & \\
\hline No & $738(56.3)$ & $389(68.2)$ & \\
\hline Alcohol use & & & 0.70 \\
\hline Yes & $46(3.5)$ & $18(3.2)$ & \\
\hline No & I,267 (96.5) & $552(96.8)$ & \\
\hline HCV genotype** & & & $<0.01$ \\
\hline 1 & $\mathrm{I}, \mathrm{I} 36(86.3)$ & $410(72.0)$ & \\
\hline 2 & $58(0.04)$ & $46(8.1)$ & \\
\hline 3 & $123(9.3)$ & $114(20.0)$ & \\
\hline IL28B polymorphism** & & & $<0.01$ \\
\hline $\mathrm{CC}$ & $27 \mid(24.0)$ & $302(74.2)$ & \\
\hline $\mathrm{CT} / \mathrm{TT}$ & $852(75.5)$ & $105(25.8)$ & \\
\hline Diabetes status & & & 0.08 \\
\hline Normal glucose & I,039 (79.I) & $439(77.0)$ & \\
\hline IFG & $168(12.8)$ & $67(11.8)$ & \\
\hline $\mathrm{T} 2 \mathrm{D}$ & $106(8.1)$ & 64 (II.2) & \\
\hline
\end{tabular}

Notes: Data are presented as mean \pm standard deviation or number (percentage). aComparisons between Asian and non-Asian chronic hepatitis $C$ patients in demographic and baseline variables were conducted using a Student's $t$-test for continuous variables and chi-square tests for categorical variables. The total number of all the categories in each variable might not equal to the sample size of Non-Asian and Asian group due to the missing value. ${ }^{*} * P<0.01$.

Abbreviations: $B M I$, body mass index; $\mathrm{HCV}$, hepatitis $\mathrm{C}$ virus; IFG, impaired fasting glucose; ND, no data; T2D, type 2 diabetes.

The distributions was reversed. No significant differences were found between Asian and non-Asian CHC participants in alcohol use, cirrhosis status, and diabetes status.

\section{Characteristics of patients by glucose abnormalities}

Baseline characteristics subclassified by glucose abnormalities are presented in Table 3. The prevalence of IFG/T2D was similar between the two populations, and there were no significant differences in the subgroup of patients $\geq 45$ years old $(P=0.50)$. BMI of those with IFG/T2D was significantly different from those with normal glucose in both the Asian and non-Asian participants (Non-Asian: $P<0.01$; Asian: $P=0.003$ ).
For Asian CHC patients, those with BMI $\geq 25$ and $<30 \mathrm{~kg} / \mathrm{m}^{2}$ had the highest prevalence of IFG/T2D, while for non-Asians, patients with $\mathrm{BMI} \geq 30 \mathrm{~kg} / \mathrm{m}^{2}$ developed more IFG/T2D than those with BMI $<30 \mathrm{~kg} / \mathrm{m}^{2}$. Generally, there were more nonAsian smokers $(43.7 \%$ vs. $31.8 \%, P<0.01)$, while among smokers, there were no statistical significant differences in Asian participants who had IFG/T2D compared to non-Asians with IFG/T2D ( $28.4 \%$ vs. $21.8 \%, P=0.10)$. Overall, patients with cirrhosis or bridging fibrosis had more IFG/T2D than those without ( $35.5 \%$ vs. $18.6 \%, P<0.01$ ). However, there was no statistically significant difference in the prevalence of IFG/T2D between Asian and non-Asian cirrhosis/bridging fibrosis patients ( $38.3 \%$ vs. $34.7 \%, P=0.42$ ).

\section{Univariate and multivariate analysis of risk factors associated with IFG/T2D}

The results of the univariate and multivariate analysis of risk factors associated with IFG/T2D are presented in Table 4 for Asians and Table 5 for non-Asians. Results revealed that age, cirrhosis status, and sex were significant as independent predictive variables associated with the presence of glucose abnormalities in Asian CHC patients, while in non-Asian CHC patients, BMI, age, sex, and cirrhosis were significant risk factors for glucose abnormalities. Older Asian patients were 3.7 times more likely to have glucose abnormalities than younger $\mathrm{CHC}$ patients, while the risk reduced to 2.1 in non-Asian $\mathrm{CHC}$ patients. Men were more likely to develop glucose abnormalities than women in both the Asian and non-Asian groups.

\section{Prevalence of glucose abnormalities (IFG/ T2D) in Asian and Western countries}

In our study, the prevalence of T2D among $\mathrm{CHC}$ patients was $11.2 \%$ in Asian countries and $8.1 \%$ in non-Asian countries, and the prevalence of IFG/T2D was $23.0 \%$ in Asian countries and $20.9 \%$ in non-Asian countries. According to IDF 2013, the prevalence of T2D was estimated to be $7.2 \%$ in Asia and $8.5 \%$ in Western countries. The prevalence of IFG/T2D was estimated to be $15.2 \%$ in Asia and $20.2 \%$ in Western countries. ${ }^{21}$

\section{Prevalence of glucose abnormalities (IFG/ T2D) between Asian and non-Asian CHC patients}

The unadjusted prevalence of glucose abnormalities (IFG/ T2D) did not differ between non-Asian and Asian CHC participants (odds ratio: $0.9,95 \%$ confidence interval: 0.8 , $1.1 ; P=0.31$ ). After adjusting for sex, age, and cirrhosis status, the prevalence of glucose abnormalities remained similar between non-Asian and Asian CHC participants (odds ratio: $1.3,95 \%$ confidence interval: $0.97,1.7 ; P=0.08$ ). 
Table 3 Characteristics of patients by glucose status

\begin{tabular}{|c|c|c|c|c|}
\hline \multirow[t]{2}{*}{ Characteristics } & \multicolumn{2}{|l|}{ Asian $(\mathrm{N}=\mathbf{5 7 0})$} & \multicolumn{2}{|c|}{ Non-Asian $(\mathbf{N}=|, 3| 7)$} \\
\hline & Normal glucose & IFG/T2D & Normal glucose & IFG/T2D \\
\hline Age (years) & $44.0 \pm 11.8$ & $50.3 \pm 10.5$ & $45.6 \pm I I .6$ & $50.7 \pm 9.5$ \\
\hline \multicolumn{5}{|c|}{ Age category (years) } \\
\hline$<45$ & $232(86.3)$ & $37(13.8)$ & $419(87.7)$ & $59(12.4)$ \\
\hline$\geq 45$ & $207(69.0)$ & $93(31.0)$ & $620(74.3)$ & $215(25.8)$ \\
\hline \multicolumn{5}{|l|}{ Sex } \\
\hline Female & $180(83.3)$ & $36(16.7)$ & $463(83.1)$ & 94 (I6.9) \\
\hline Male & $259(73.2)$ & $95(26.9)$ & $576(76.2)$ & $180(23.8)$ \\
\hline BMI $\left(\mathrm{kg} / \mathrm{m}^{2}\right)$ & $24.1 \pm 3.5$ & $25.4 \pm 2.8$ & $26.0 \pm 4.2$ & $27.9 \pm 4.0$ \\
\hline \multicolumn{5}{|c|}{ BMI category $\left(\mathrm{kg} / \mathrm{m}^{2}\right)$} \\
\hline$\geq 30$ & $25(80.7)$ & $6(19.3)$ & $172(68.3)$ & $80(31.8)$ \\
\hline$\geq 25$ and $<30$ & $|3|(68.2)$ & $61(31.8)$ & $404(76.8)$ & $122(23.2)$ \\
\hline$<25$ & $283(81.6)$ & $64(18.5)$ & $46 \mid(86.7)$ & $71(13.4)$ \\
\hline \multicolumn{5}{|l|}{ Smoking } \\
\hline Yes & $129(7 \mid .3)$ & $52(28.8)$ & $449(78.5)$ & $123(21.6)$ \\
\hline No & $310(79.7)$ & $79(20.3)$ & 587 (79.7) & $150(20.4)$ \\
\hline \multicolumn{5}{|l|}{ Alcohol use } \\
\hline Yes & $13(72.2)$ & $5(27.8)$ & $36(78.3)$ & $10(21.8)$ \\
\hline No & $426(77.2)$ & $126(22.8)$ & $\mathrm{I}, 00 \mathrm{I}(96.5)$ & $264(192.3)$ \\
\hline \multicolumn{5}{|l|}{ HCV genotype } \\
\hline I & $310(75.6)$ & $100(24.4)$ & $895(79.1)$ & $237(20.9)$ \\
\hline 2 & $35(76.1)$ & II (23.9) & $49(84.7)$ & $9(15.5)$ \\
\hline 3 & $94(82.5)$ & $20(17.5)$ & $95(77.2)$ & $28(22.8)$ \\
\hline \multicolumn{5}{|c|}{ IL28B polymorphism } \\
\hline $\mathrm{CC}$ & $232(76.8)$ & $70(23.2)$ & $217(80.1)$ & $54(19.9)$ \\
\hline $\mathrm{CT} / \mathrm{TT}$ & 75 (7I.4) & $30(28.6)$ & $669(78.5)$ & $183(2 \mid .5)$ \\
\hline \multicolumn{5}{|c|}{ Cirrhosis or bridging fibrosis } \\
\hline Yes & $50(6 \mid .7)$ & $21(28.3)$ & $164(65.3)$ & $87(34.6)$ \\
\hline No & $312(79.4)$ & $81(20.6)$ & $774(82.6)$ & $163(17.4)$ \\
\hline
\end{tabular}

Note: Data are presented as mean \pm standard deviation or number (percentage).

Abbreviations: BMI, body mass index; HCV, hepatitis C virus; IFG, impaired fasting glucose; T2D, type 2 diabetes.

\section{Impact of IFG/T2D on the virologic response to pegIFN/RBV treatment}

In the control arms, genotype 1 naïve or treatment-experienced patients received 48 weeks of treatment with pegIFN once a week plus RBV, while the genotype $2 / 3$ patients received
24 weeks of treatment. SVR data were pooled together and SVR rates were compared by glucose status as well as Asian or non-Asian races (Figure 1). There was 111 Asian and 243 non-Asian patients that were treated with pegIFN/RBV. Both in Asian and non-Asian CHC patients,

Table 4 Unadjusted and adjusted risk factors associated with the development of IFG/T2D in Asian CHC patients

\begin{tabular}{|c|c|c|c|c|}
\hline \multirow[t]{2}{*}{ Variable } & \multicolumn{2}{|c|}{ Univariate analysis } & \multicolumn{2}{|c|}{ Multivariate analysis } \\
\hline & OR (95\% CI) & $P$-value ${ }^{a}$ & OR $(95 \% \mathrm{Cl})$ & $P$-value ${ }^{b}$ \\
\hline Age, $<45$ years & $2.8(1.8,4.3)$ & $<0.01 * *$ & $3.7(2.2,6.3)$ & $<0.01 * *$ \\
\hline Sex, female & $1.8(1.2,2.8)$ & $0.006 * *$ & $2.3(1.4,3.7)$ & $0.00 I^{* *}$ \\
\hline \multicolumn{5}{|l|}{ BMI categories kg/m² } \\
\hline$\geq 30$ vs $<25$ & I.I $(0.4,2.7)$ & 0.90 & - & - \\
\hline$\geq 25$ and $<30$ vs $<25$ & $2.1(1.4,3.1)$ & $<0.01 * *$ & - & - \\
\hline Cirrhosis, no & $2.4(1.4,4.0)$ & $<0.01 * *$ & $1.95(1.14,3.33)$ & $0.01 *$ \\
\hline Alcohol use, no & $1.3(0.5,3.7)$ & 0.62 & - & - \\
\hline Smoking, no & $1.6(1.1,2.4)$ & $0.03 *$ & - & - \\
\hline IL28B polymorphism, non-CC & $1.3(0.8,2.2)$ & 0.27 & - & - \\
\hline \multicolumn{5}{|l|}{$\mathrm{HCV}$ genotype } \\
\hline 2 vs I & $0.97(0.48,1.99)$ & 0.94 & - & - \\
\hline 3 vs I & $0.66(0.39,1.12)$ & 0.13 & - & - \\
\hline
\end{tabular}

Notes: anivariate logistic regression was carried out to test the potential risk factors of the glucose abnormality of the participants. ${ }^{\mathrm{b}}$ The multivariate logistic regression model was adopted to find the predictive factors among those significant in the previous univariate analyses. $* P<0.05$; $* * P<0.0$ I.

Abbreviations: BMI, body mass index; CHC, chronic hepatitis C; Cl, confidence interval; HCV, hepatitis C virus; IFG, impaired fasting glucose; OR, odds ratio; T2D, type 2 diabetes. 
Table 5 Unadjusted and adjusted risk factors associated with the development of IFG/T2D in non-Asian CHC patients

\begin{tabular}{|c|c|c|c|c|}
\hline \multirow[t]{2}{*}{ Variable } & \multicolumn{2}{|c|}{ Univariate analysis } & \multicolumn{2}{|c|}{ Multivariate analysis } \\
\hline & OR $(95 \% \mathrm{Cl})$ & $P$-value ${ }^{a}$ & OR $(95 \% \mathrm{Cl})$ & $P$-value ${ }^{b}$ \\
\hline Age, $<45$ years & $2.5(1.8,3.4)$ & $<0.01 * *$ & $2.1(1.5,3.0)$ & $<0.01 * *$ \\
\hline Sex, female & $1.5(1.2,2.0)$ & $0.002^{* *}$ & $1.4(1.0,1.9)$ & $0.04^{*}$ \\
\hline \multicolumn{5}{|l|}{ BMI categories $\mathrm{kg} / \mathrm{m}^{2}$} \\
\hline$\geq 30$ vs $<25$ & $3.0(2.1,4.3)$ & $<0.0 \mathrm{I}^{* *}$ & $2.3(1.0,1.9)$ & $<0.01 * *$ \\
\hline$\geq 25$ and $<30$ vs $<25$ & $1.96(1.4,2.7)$ & $<0.01 * *$ & $1.6(1.0,1.9)$ & $0.01 * *$ \\
\hline Cirrhosis, no & $2.5(1.8,3.4)$ & $<0.01 * *$ & $1.9(1.4,2.7)$ & $<0.01 * *$ \\
\hline Alcohol use, no & I.I $(0.5,2.2)$ & 0.89 & - & - \\
\hline Smoking, no & I.I $(0.8,1.4)$ & 0.61 & - & - \\
\hline IL28B polymorphism, non-CC & I.I $(0.8,1.5)$ & - & - & - \\
\hline \multicolumn{5}{|l|}{ HCV genotype } \\
\hline 2 vs 1 & $0.7(0.3,1.4)$ & 0.32 & - & - \\
\hline 3 vs 1 & I.I $(0.7,1.7)$ & 0.64 & - & - \\
\hline
\end{tabular}

Notes: aUnivariate logistic regression was carried out to test the potential risk factors of the glucose abnormality of the participants. ${ }^{\text {} T \text { The multivariate logistic regression }}$ model was adopted to find the predictive factors among those significant in the previous univariate analyses. ${ }^{*} P<0.05 ; * * P<0.01$.

Abbreviations: $\mathrm{BMI}$, body mass index; $\mathrm{CHC}$, chronic hepatitis $\mathrm{C} ; \mathrm{Cl}$, confidence interval; $\mathrm{HCV}$, hepatitis $\mathrm{C}$ virus; IFG, impaired fasting glucose; OR, odds ratio; T2D, type 2 diabetes.

there were no statistically significant differences in SVR rate between patients with IFG/T2D and those with normal fasting glucose, despite the fact that there were many more treatment-experienced patients in the IFG/T2D group (treatment-experienced patients in the IFG/T2D group vs the normal glucose group for Asian patients: $28.0 \%$ vs $5.8 \%$, $P=0.002$; for non-Asian patients: $24.5 \%$ vs $12.6 \%, P=0.03$ ). When comparing the SVR rates within the same glucose status, the rate in Asian normal fasting glucose participants was as much as $16 \%$ higher than in non-Asians $(P<0.01)$, and Asian participants with glucose abnormalities showed a $32 \%$ higher SVR rate than non-Asians $(P<0.01)$.

\section{Discussion}

This study retrospectively analyzed data from 1,887 CHC patients in three Phase II or III studies with ALV as treatment for chronic HCV infection to explore whether Asian CHC patients had a similar prevalence of glucose abnormalities (IFG/T2D) to non-Asian patients and to compare the risk factors of IFG/T2D in these two populations and evaluated whether glucose abnormalities impacted the viral responses to $\mathrm{pegIFN/RBV}$.

An association of HCV infection with diabetes has been found in most clinical studies comparing noninfected controls and patient samples. ${ }^{3,4}$ In 1994, Allison et al reported

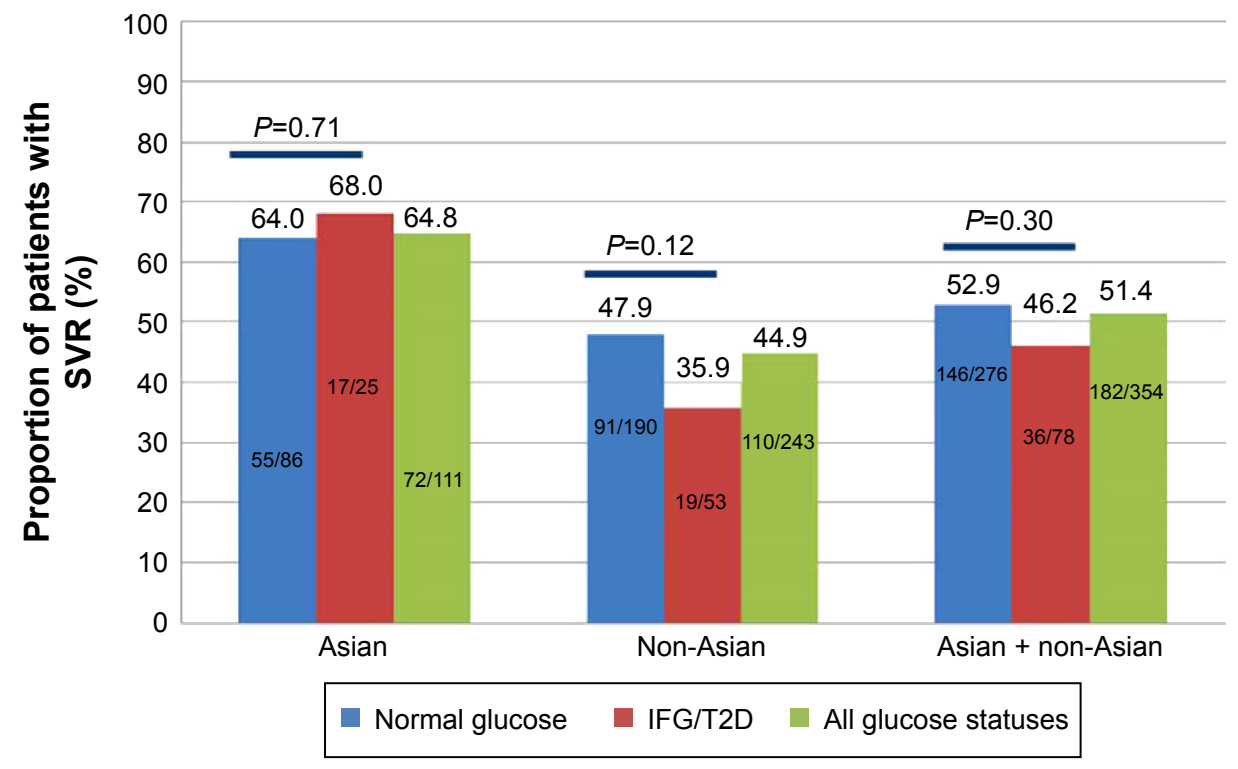

Figure I Patients who received peginterferon plus ribavirin and achieved SVR by glucose abnormalities. Abbreviations: IFG, impaired fasting glucose; SVR, sustained virological response; T2D, type 2 diabetes. 
for the first time that cirrhotic patients infected with $\mathrm{HCV}$ presented with T2D more often than patients with cirrhosis of other etiologies. ${ }^{23}$ Subsequently, several cross-sectional studies comparing the prevalence of T2D between CHC patients and a comparator group supported the assertion. ${ }^{5-10}$ The Third National Health and Nutrition Examination Survey (NHANES III) showed that, in the USA, HCV-positive patients aged 40 years or above were over three times more likely to have T2D than those without chronic HCV infection. ${ }^{24,25}$ A similar result was reported in AmericanIndian women who were receiving prenatal care. ${ }^{26}$ Insulin resistance has been reported in 32\%-70\% of HCV patients, ${ }^{27}$ and the prevalence of T2D was $14 \%-50 \%$ in patients with chronic HCV infection. ${ }^{28}$ Fallahi et al summarized in their review that approximately 68 studies globally (cutoff date December 2012) were in agreement that there was an association between these two diseases, even though not all of them had provided statistically significant data. ${ }^{29}$

In our study, the prevalence of T2D and IFG/T2D in Asian CHC patients was higher than the IDF-reported prevalence among the general population. ${ }^{21}$ Since those with uncontrolled diabetes, those older than 70 years, and those with BMI $>36 \mathrm{~kg} / \mathrm{m}^{2}$ were excluded from our studies, the real prevalences of T2D and IFG/T2D (abnormal glucose) among $\mathrm{CHC}$ patients (chronic HCV infection) were expected to be higher than our report, and also higher than IDF-reported. This suggested the potential correlation between chornic $\mathrm{HCV}$ infection and abnormal glucose. However, the prevalence of T2D and IFG/T2D in nonAsian CHC patients looked similar to that reported in the IDF 2013 general population. ${ }^{21}$ This may be explained by the fact that more non-Asian $\mathrm{CHC}$ patients were excluded from our studies due to having a BMI >36 compared to Asian CHC patients. However, further study is needed to confirm this relationship (the correlation between chronic $\mathrm{HCV}$ infection and abnormal glucose) in both populations. Furthermore, our study compared the prevalence of IFG/ T2D between Asian CHC patients and non-Asian patients, which was never studied before, and we found that there was no significant difference between these two populations in prevalence of IFG/T2D.

However, the risk factors associated with IFG/T2D varied between the two populations. Both age and sex showed a stronger association with glucose abnormalities in Asian than non-Asian CHC patients. The impact of cirrhosis was similar in Asian and non-Asian CHC patients. However, BMI was positively associated with glucose abnormalities only in non-Asian CHC patients. This may be explained by a lower mean BMI in the Asian compared with the non-Asian population, and the small proportion of participants with a high BMI. Alcohol use, viral (HCV genotype), and host IL28B polymorphism were not found to be associated with the development of glucose abnormalities in either Asian or non-Asian CHC participants. A literature review of alcohol and T2D found long-term alcohol use seems to be associated with improved glycemic control in T2D, probably due to improved insulin sensitivity, while binge drinking seems to increase the incidence. ${ }^{30}$ In all three studies, alcohol consumption $>20 \mathrm{~g} /$ day for females and $>30 \mathrm{~g} /$ day for males was an exclusion criterion, which excluded binge drinkers from our studies. From the data supporting the association of $\mathrm{HCV}$ infection and T2D, it was found that comparator groups may have differed from $\mathrm{HCV}$-infected patients in terms of risk factors for T2D, such as age, male sex, and liver fibrosis stage. When analysis was carried out based on appropriate stratifications, we found that advancing age, obesity, cirrhosis, family history of diabetes, African-American origin, and HIV coinfection were recognized as factors associated with diabetes development among HCV-infected patients. ${ }^{11,31,32}$ Several additional case-control studies have also confirmed the effect of other risk factors on the association of $\mathrm{CHC}$ to T2D. ${ }^{33-40}$ Overall, it appears that the difference in T2D prevalence between populations may reflect the effect of other risk factors on glucose abnormalities and T2D more than HCV status.

In many Asian countries, especially in the People's Republic of China, pegIFN/RBV remains the standard of care. Thus, we explored whether glucose abnormalities have an impact on viral responses to pegIFN/RBV treatment. No significant differences in SVR rates were seen between patients with normal fasting glucose vs patients with glucose abnormalities, which was the case for both Asian and nonAsian participants. We also found that SVR rates in Asian $\mathrm{CHC}$ patients were much higher than in non-Asian patients within the same glucose status. The higher response rate may be partially explained by the predominance of the favorable IL28B genotype CC observed in Asian participants compared with non-Asians (rs12979860, 74.2\% vs 24\%; $P<0.01$ ). Another reason might be that RBV was given at a fixed dose of $800 \mathrm{mg}$ daily for HCV genotype 2 or 3 treatment-naïve patients in study A2211 per accepted standards of care. In study A2211, Asians weighed less than non-Asians $(67.0 \mathrm{~kg}$ vs $79.1 \mathrm{~kg}$ ), while the SVR rate in Asian patients was higher ( $82.4 \%$ vs $47.8 \%$ ), which can be explained by higher RBV exposure when given the same dosage. Low relapse rates were reported with RBV at a weight-based dosage when 
in combination with pegIFN. ${ }^{41-45}$ Therefore, the efficacy results in this study are in concordance with other pegIFN/ RBV treatment studies. Based on the higher percentage of treatment-experienced patients in the Asian group, one might have expected a lower SVR rate in this population based on this negative predictor of response.

The strengths of this study are that it has large numbers of both Asian and non-Asian patients treated in wellmonitored studies using a central laboratory and databases. Potential limitations include the exclusion of patients based on a BMI threshold of $36 \mathrm{~kg} / \mathrm{m}^{2}$, a history of uncontrolled diabetes mellitus or retinopathy, and other severe comorbidities. In addition, we did not collect hip-to-waist ratio, which is a strong predictor for the prevalence of glucose abnormalities.

\section{Conclusion}

Our study indicates that the prevalence of glucose abnormalities was more than $20 \%$ in both Asian and non-Asian CHC patients, and the prevalence in Asians was similar to that in non-Asians. Those of older age, male sex, or having cirrhosis were more likely to develop glucose abnormalities both in Asian and non-Asian CHC patients. BMI was positively associated with glucose abnormalities in non-Asian $\mathrm{CHC}$ patients but not in Asian CHC patients. Glucose abnormalities did not appear to be substantially associated with achievement of SVR when treated with pegIFN/RBV, especially in Asian participants. Asian $\mathrm{CHC}$ patients showed better response rates on pegIFN/RBV treatment than non-Asian $\mathrm{CHC}$ patients, whether glucose status was normal or not.

The real-life problems with IFG and T2D in CHC patients might be more serious than we observed in this study. This suggests that individuals with $\mathrm{CHC}$ should change their lifestyle and dietary habits proactively to prevent the occurrence of glucose abnormalities.

\section{Author contributions}

Bo Q conceived of the study, supervised all aspects of its implementation, and led the writing. Wang J completed the analyses. Orsenigo R, Griffel L, and Brass C assisted with the study and analyses. All authors helped to conceptualize ideas, interpret findings, and review drafts of the manuscript. All authors contributed toward data analysis, drafting and revising the paper and agree to be accountable for all aspects of the work.

\section{Disclosure}

The authors report no conflicts of interest in this work.

\section{References}

1. Mohd Hanafiah K, Groeger J, Flaxman AD, Wiersma ST. Global epidemiology of hepatitis $C$ virus infection: new estimates of age-specific antibody to HCV seroprevalence. Hepatology. 2013;57(4):1333-1342.

2. Lee MH, Yang HI, Lu SN, et al; R.E.V.E.A.L.-HCV Study Group. Chronic hepatitis $\mathrm{C}$ virus infection increases mortality from hepatic and extrahepatic diseases: a community-based long-term prospective study. J Infect Dis. 2012;206:469-477.

3. Naing C, Mak JW, Ahmed SI, Maung M. Relationship between hepatitis $\mathrm{C}$ virus infection and type 2 diabetes mellitus: meta-analysis. World J Gastroenterol. 2012;18:1642-1651.

4. White DL, Ratziu V, El-Serag HB. Hepatitis C infection and risk of diabetes: a systematic review and meta-analysis. J Hepatol. 2008;49:831-844.

5. Mason AL, Lau JY, Hoang N, et al. Association of diabetes mellitus and chronic hepatitis C virus infection. Hepatology. 1999;29:328-333.

6. Zein NN, Abdulkarim AS, Wiesner RH, Egan KS, Persing DH. Prevalence of diabetes mellitus in patients with end-stage liver cirrhosis due to hepatitis C, alcohol, or cholestatic disease. J Hepatol. 2000;32: 209-217.

7. Howard AA, Klein RS, Schoenbaum EE. Association of hepatitis C infection and antiretroviral use with diabetes mellitus in drug users. Clin Infect Dis. 2003;36:1318-1323.

8. Lecube A, Hernández C, Genescà J, Esteban JI, Jardí R, Simó R. High prevalence of glucose abnormalities in patients with hepatitis $\mathrm{C}$ virus infection: a multivariate analysis considering the liver injury. Diabetes Care. 2004;27:1171-1175.

9. Huang JF, Dai CY, Hwang SJ, et al. Hepatitis C viremia increases the association with type 2 diabetes mellitus in a hepatitis $\mathrm{B}$ and $\mathrm{C}$ endemic area: an epidemiological link with virological implication. Am J Gastroenterol. 2007;102:1237-1243.

10. Imazeki F, Yokosuka O, Fukai K, Kanda T, Kojima H, Saisho H. Prevalence of diabetes mellitus and insulin resistance in patients with chronic hepatitis C: comparison with hepatitis B virus-infected and hepatitis C virus-cleared patients. Liver Int. 2008;28:355-362.

11. Mehta SH, Brancati FL, Strathdee SA, et al. Hepatitis C virus infection and incident type 2 diabetes. Hepatology. 2003;38:50-56.

12. Huang J. The incidence of diabetes in patients with chronic hepatitis. Infectious Disease Information. 2008;1:56-57. Chinese.

13. Rong X, Qiu Z, Zhou L. Clinical analysis of 91 cases of hepatic diabetes. Contemporary Chinese Medicine. 2009;6:166-168. Chinese.

14. Ghany MG, Nelson DR, Strader DB, Thomas DL, Seeff LB; American Association for Study of Liver Diseases. An update on treatment of genotype 1 chronic hepatitis $\mathrm{C}$ virus infection: 2011 practice guideline by the American Association for the Study of Liver Diseases. Hepatology. 2011;54(4):1433-1444.

15. Yu ML, Chuang WL. Treatment of chronic hepatitis C in Asia: when East meets West. J Gastroenterol Hepatol. 2009;24(3):336-345.

16. Romero-Gómez M, Fernández-Rodríguez CM, Andrade RJ, et al. Effect of sustained virological response to treatment on the incidence of abnormal glucose values in chronic hepatitis C. J Hepatol. 2008; 48:721-727.

17. HUGO Pan-Asian SNP Consortium, Abdulla MA, Ahmed I, et al; Indian Genome Variation Consortium. Mapping human genetic diversity in Asia. Science. 2009;326(5959):1541-1545.

18. Arena U, Vizzutti F, Abraldes JG, et al. Reliability of transient elastography for the diagnosis of advanced fibrosis in chronic hepatitis $\mathrm{C}$. Gut. 2008;57:1288-1293.

19. American Diabetes Association. Diagnosis and Classification of Diabetes Mellitus. Diabetes Care. 2010;33(Suppl 1):S62-S69.

20. World Health Organization International Diabetes Federation. Definition and diagnosis of diabetes mellitus and intermediate hyperglycaemia: report of a WHO/IDF consultation. 2006. Available from: http://www.who.int/iris/handle/10665/43588\#sthash.PemL71JY.dpuf. Accessed October 14, 2015.

21. IDF Diabetes Atlas Sixth Edition Update 2013. Brussels: International Diabetes Federation (IDF). Available from: https://www.idf.org/sites/ default/files/EN_6E_Atlas_Full_0.pdf. Accessed May 19, 2014. 
22. World Health Organization. Waist circumference and waist-hip ratio: report of a WHO expert consultation. Geneva, World Health Organization, 2008. Available from: http://apps.who.int/iris/bitstream/10665/4 4583/1/9789241501491_eng.pdf. Accessed October 14, 2015.

23. Allison ME, Wreghitt T, Palmer CR, Alexander GJ. Evidence for a link between hepatitis $\mathrm{C}$ virus infection and diabetes mellitus in a cirrhotic population. J Hepatol. 1994;21:1135-1139.

24. Mehta SH, Brancati FL, Sulkowski MS, Strathdee SA, Szklo M, Thomas DL. Prevalence of type 2 diabetes mellitus among persons with hepatitis C virus infection in the United States. Ann Intern Med. 2000;133:592-599.

25. Mehta SH, Brancati FL, Sulkowski MS, Strathdee SA, Szklo M, Thomas DL. Prevalence of type 2 diabetes mellitus among persons with hepatitis C virus infection in the United States. Hepatology. 2001;33: 1554.

26. Wilson C. Hepatitis $\mathrm{C}$ infection and type 2 diabetes in American-Indian women. Diabetes Care. 2004;27:2116-2119.

27. Hanouneh IA, Feldstein AE, Lopez R, et al. Clinical significance of metabolic syndrome in the setting of chronic hepatitis $\mathrm{C}$ virus infection. Clin Gastroenterol Hepatol. 2008;6:584-589.

28. Harrison SA. Liver disease in patients with diabetes mellitus. J Clin Gastroenterol. 2006;40:68-76.

29. Fallahi P, Ferrari SM, Colaci M, et al. Hepatitis C virus infection and type 2 diabetes. Clin Ter. 2013;164(5):e393-e404.

30. Pietraszek A, Gregersen S, Hermansen K. Alcohol and type 2 diabetes. A review. Nutr Metab Cardiovasc Dis. 2010;20(5):366-375.

31. Thuluvath PJ, John PR. Association between hepatitis C, diabetes mellitus, and race: a case-control study. Am J Gastroenterol. 2003;98: 438-441.

32. Butt AA, Fultz SL, Kwoh CK, Kelley D, Skanderson M, Justice AC. Risk of diabetes in HIV infected veterans pre- and post-HAART and the role of HCV coinfection. Hepatology. 2004;40:115-119.

33. Ozyilkan E, Arslan M. Increased prevalence of diabetes mellitus in patients with chronic hepatitis C virus infection. Am J Gastroenterol. 1996;91: 1480-1481.

34. Caronia S, Taylor K, Pagliaro L, et al. Further evidence for an association between non-insulin-dependent diabetes mellitus and chronic hepatitis C virus infection. Hepatology. 1999;30:1059-1063.
35. El-Serag HB, Hampel H, Yeh C, Rabeneck L. Extrahepatic manifestations of hepatitis $\mathrm{C}$ among United States male veterans. Hepatology. 2002;36:1439-1445.

36. Hirakauva EY, Ferraz ML, Perez RM, et al. Prevalence of diabetes mellitus in renal transplant patients with hepatitis $\mathrm{B}$ or $\mathrm{C}$ virus infection. Transplant Proc. 2002;34:3220-3222.

37. Antonelli A, Ferri C, Fallahi P, et al. Hepatitis C virus infection: evidence for an association with type 2 diabetes. Diabetes Care. 2005;28:2548-2550.

38. Huang JF, Yu ML, Dai CY, et al. Reappraisal of the characteristics of glucose abnormalities in patients with chronic hepatitis $\mathrm{C}$ infection. Am J Gastroenterol. 2008;103:1933-1940.

39. Zein CO, Levy C, Basu A, Zein NN. Chronic hepatitis C and type II diabetes mellitus: a prospective cross-sectional study. Am J Gastroenterol. 2005;100:48-55.

40. Memon MS, Arain ZI, Naz F, Zaki M, Kumar S, Burney AA. Prevalence of type 2 diabetes mellitus in hepatitis $\mathrm{C}$ virus infected population: a Southeast Asian study. J Diabetes Res. 2013;2013:539361.

41. Bochud PY, Cai T, Overbeck K, et al; Swiss Hepatitis C Cohort Study Group. Genotype 3 is associated with accelerated fibrosis progression in chronic hepatitis C. J Hepatol. 2009;51(4):655-666.

42. Dalgard O, Bjøro K, Hellum KB, et al. Treatment with pegylated interferon and ribavirin in HCV infection with genotype 2 or 3 for 14 weeks: a pilot study. Hepatology. 2004;40:1260-1265.

43. Dalgard O, Bjøro K, Ring-Larsen H, et al; North-C Group. Pegylated interferon alfa and ribavirin for 14 versus 24 weeks in patients with hepatitis $\mathrm{C}$ virus genotype 2 or 3 and rapid virological response. Hepatology. 2008;47(1):35-42.

44. Mangia A, Santoro R, Minerva N, et al. Peginterferon alfa-2b and ribavirin for 12 vs. 24 weeks in HCV genotype 2 or 3. N Engl J Med. 2005; 352:2609-2617.

45. von Wagner H, Huber H, Berg T, et al. Peginterferon-alpha-2a (40 KD) and ribavirin for 16 or 24 weeks in patients with genotype 2 or 3 chronic hepatitis C. Gastroenterology. 2005;129(2):522-527.

\section{Publish your work in this journal}

Drug Design, Development and Therapy is an international, peerreviewed open-access journal that spans the spectrum of drug design and development through to clinical applications. Clinical outcomes, patient safety, and programs for the development and effective, safe, and sustained use of medicines are a feature of the journal, which

\section{Dovepress}

has also been accepted for indexing on PubMed Central. The manuscript management system is completely online and includes a very quick and fair peer-review system, which is all easy to use. Visit http://www.dovepress.com/testimonials.php to read real quotes from published authors. 